\title{
PENERAPAN METODE EKSPERIMEN UNTUK MENINGGKATKAN PROSES SAINS DAN HASIL BELAJAR SISWA (USAHA DAN ENERGI KELAS X SMA NEGERI 1 TONDANO)
}

\author{
Asterlita Tirsa Raha, Heinrich Taunaumang, Jeane Tumangkeng \\ Fakultas Matematika dan Ilmu Pengetahuan Alam, Universitas Negeri Manado \\ email: asterlitatirsa@gmail.com
}

\begin{abstract}
ABSTRAK
Fisika adalah salah satu mata pelajaran yang diajarkan di Sekolah Menenga Atas (SMA) dan merupakan mata pelajaran yang amat ditakuti oleh peserta didik, berbagai mitos yang mempengaruhi motivasi serta berakibat pada hasil belajar siswa. Pembelajaran fisika sudah banyak dijelaskan bukan hanya pembelajaran berupa transfer ilmu namun sebuah proses konstruktivisme yang memfasilitasi siswa untuk melatih keterampilan, membangun kognitifnya sendiri dan menumbuhkan sikap positif. Tujuan penelitian ini untuk mengetahui : (1) peningkatan hasil belajar siswa SMA Negeri 1 Tondano pada kelas $\mathrm{X}$ materi usaha dan energi dengan menggunakan metode eksperimen. (2) peningkatan keterampilan proses sains pada siswa SMA Negeri 1 Tondano kelas X pada materi usaha dan energi dengan menggunakan metode eksperimen. Menggunakan penelitian eksperimental kualitatif dan kuantitatif. Peningkatan hasil belajar dan keterampilan proses sains berdasarkan pretest dan post tes dianalisis dengan uji t secara statistik menggunakan program SPSS. Hasil penelitian menunjukan bahwa Penggunaan metode eksperimen dapat meningkatkan hasil belajar siswa dengan $t$ hitung 2,763>1669 t tabel maka $\mathrm{H}_{0}$ ditolak dan $\mathrm{H}_{a}$. Penggunaan metode eksperimen dapat meningkatkan keterampilan proses sains dengan t hitung 5,011, dengan demikian $\mathrm{t}$ hitung 5,011>1,669 t tabel maka ${ }^{1} \mathrm{H}_{0}$ ditolak. Dan $\mathrm{H} \alpha$. Metode pembelajaran eksperimen layak dipertimbangkan dalam menyusun strategi pembelajaran fisika.
\end{abstract}

Kata kunci: Metode eksperimen, Usaha dan energi, Keterampilan proses sains

\section{ABSTRACT}

Physics is one of the subjects taught in high School (SMA) and is a subject that is greatly feared by students, various myths that affect motivation and have an impact on student learning outcomes. Physics learning has been described not only as learning in the form of knowledge transfer but a constructivist process that facilitates students to practice skills, build their own cognitive skills and foster positive attitudes. The purpose of this study was to determine: (1) the improvement of student learning outcomes at SMA Negeri 1 Tondano in class X on business and energy materials using the experimental method. (2) the improvement of science process skills in students of SMA Negeri 1 Tondano class $X$ in the business and energy materials using the experimental method. Using qualitative and quantitative experimental research. Improved learning outcomes and science process skills based on the pretest and posttest were analyzed by statistical t-test using the SPSS program. The results showed that the use of the experimental method can improve student learning outcomes with $t$ count 2.763> 1669 t table, so $H_{0}$ is rejected and $\mathrm{Ha}$. The use of the experimental method can improve science process skills with $t$ count 5.011, thus $t$ count 5.011> 1.669 t table then ${ }^{1} H_{0}$ is rejected. And $H \alpha$. Experimental learning methods are worth considering in developing physics learning strategies.

Keywords: Experimental methods, Work and energy, Science process skills 


\section{PENDAHULUAN}

Pendidikan adalah usaha sadar dan terencana untuk mewujudkan suasana belajar dan proses pembelajaran agar peserta didik secara aktif mengembangkan potensi dirinya untuk memiliki kekuatan spiritual keagamaan, pengendalian diri, kepribadian, kecerdasan, akhlak mulia, serta keterampilan yang diperlukan dirinya, masyarakat, bangsa dan negara. (UU No.20 tahun 2003)

Pembelajaran fisika sudah banyak dijelaskan bukan hanya pembelajaran berupa transfer ilmu namun sebuah proses konstruktivisme yang memfasilitasi siswa untuk melatih keterampilan, membangun kognitifnya sendiri dan menumbuhkan sikap positif (Kurniawan, 2014).

Tepatnya tahun 2017 semester genap, penulis mengikuti Program Pengalaman Lapangan (PPL II) yang dilaksanakan oleh UPT Unima di SMA Negeri 1 Tondano, yang merupakan sekolah dengan akreditasi A di kabupaten Minahasa. Para ahli berpendapat tentang metode eksperimen antara lain :

1. Menurut Syaiful Bahri Djamal (N. Ardi Setyanto; 2014 :184), metode eksperimen adalah cara penyajian pelajaran dimana murid melakukan percobaan dengan mengalami dan membuktikan sendiri sesuatu yang dipelajari.

2. Menurut Roestiyah (N. Ardi Setyanto; 2014 :184), metode eksperimen merupakan salah satu cara mengajar, dimana murid melakukan percobaan tentang sesuatu, mengamati proses, menuliskan hasil percobaan, kemudian menyampaikan hasil pengamatan didalam kelas untuk dievaluasi oleh guru.

3. Menurut Mulyani Sumantri (N. Ardi Setyanto; 2014 :185), metode eksperimen merupakan cara belajar yang melibatkan murid dengan mengalami dan membuktikan sendiri proses dan hasil percobaan.

Berdasarkan kelebihan metode eksperimen diatas maka akan mempengaruhi hasil belajar dan keterampilan proses sains siswa. Menurut Bloom hasil belajar dalam ranah kognitif ada enam tingkatan yaitu mengenal, pemahaman, penerapan, analisis, sintesis dan evaluasi (Anderson dan Krathwolh, 2001). Dan untuk penelitian ini diukur oleh hasil pretest dan post test siswa.

Proses dalam melakukan aktivitas yang berhubungan dengan sains biasanya disebut keterampilan proses sains (Science process skills). Keterampilan proses sains merupakan kemampuan peserta didik dalam menerapkan metode ilmiah dalam memahami, mengembangkan sains seta menemukan ilmu pengetahuan (Afrizon, Rantawulan, \& Fauzi, 2012).

Tepatnya tahun 2017 semester genap, saya mengikuti Program Pengalaman Lapangan (PPL II) yang dilaksanakan oleh UPT Unima di SMA Negeri 1 Tondano, yang merupakan sekolah dengan akreditasi A di kabupaten Minahasa. Didapati bahwa siswa cenderung tak menyukai pelajaran fisika, berdasarkan hasil observasi dan wawancara terhadap peserta didik, penulis temukan bahwa sebagian besar siswa mengeluhkan hal yang sama yakni terlalu banyak rumus, hitungan, konsep serta hukumhukum yang amat sukar. Di tambah dengan proses pembelajaran yang terus berpusat pada guru dan terkesan monoton serta tidak menarik. Alhasil, nilai akhir pembelajaran fisika selalu rendah dan selalu dilaksanakan remedial.

Menurut Mulyani Sumantri (N. Ardi Setyanto;2014) menyatakan bahwa "metode eksperimen adalah cara belajar yang melibatkan murid dengan mengalami dan membuktikan sendiri proses dan hasil percobaan. Adapun menurut Schoenherr " metode eksperimen adalah metode yang paling sesuai diterapkan dalam pembelajaran dibidang sains. Sebab pembelajaran yang menggunakan metode eksperimen memungkinkan murid mendapatkan kesempatan untuk mengalami atau menyelesaikan masalah secara langsung.

Kenyataan bahwa rendahnya hasil belajar siswa dan proses saintifik dalam pembelajaran fisika adalah tanggung-jawab pendidik, dengan menganalisis karakteristik siswa dan menguasai materi ajar serta menggunakan strategi belajar mengajar yang tepat niscaya pembelajaran fisika akan kembali diminati dan menarik peserta didik yang berimplikasi para peningkatan proses saintifik dan hasil belajar siswa.

Berdasarkan hal diatas, peneliti merasa tertarik sekaligus tertantang untuk mengkaji lebih jauh, melalui penelitian berjudul :

"Penerapan Metode Eksperimen untuk Meninggkatkan Proses Keterampilan Sains 


\section{dan Hasil Belajar Siswa (Usaha dan Energi kelas X SMA Negeri 1 Tondano)"}

\section{METODE PENELITIAN}

Subjek penelitian diambil dari SMA Negeri 1 Tondano pada semester ganjil tahun ajaran 2018/2019. Dalam penelitian menggunakan kelompok 1 eksperimental dan 1 kelompok kontrol. Dengan jumlah siswa 58 siswa, di bagi menjadi 2 kelompok dengan Teknik pengambilan sample secara acak dan menggunakan Teknik simple ramdom sampling tanpa memperhatkan strata yang ada pada populasi.

Desain penelitian menggunakan pre-test and post-test control group. Pre-test dan pst-tes control group adalah desain penelitian yang terdiri dari dua kelompok yaitu kelompok eksperimen dan kelompok control. Setiap siswa dibagi dalam dua kelompok, kelompok eksperimen diberikan variable eksperimen dan kelompok kontrol tidak diberikan variable eksperimen. Proses pembelajaran dimulai dengan diberikan tes pertama (pre-test) bagi kedua kelompok, agar mengetahui sejauh mana penguasaan materi tehadap materi usaha dan energi pada ke-58 siswa dan siswi di SMA Negeri 1 Tondano.

Setelah pre-tes dilaksanakan pada pertemuan pertama, selanjutnya proses pembelajaran dimulai. Pada kelas eksperimen di berikan metode eksperimen dan kelas control diberikan ceramah aktif. Setelah treatment dilaksanakan pada kedua kelas eksperimen dan control, di akhiri dengan memberikan tes terakhir (post-test) untuk mengetahui peningkatan hasil belajar siswa dan keterampilan proses sains pada siswa dan siswi SMA Negeri 1 Tondano kelas X.

1. Uji Prasyarat

a. Uji Normalitas

Agar dapat mengetahui normalitas sample masing-masing sampel (kelompok siswa) maka dilakukan pengujian normalitas. Diuji dengan menggunakan software SPSS 22,0. Dalam pengujian normalitas setiap kelompok sampel, selalu diuji hipotesis kenormalan. Hipotesis nol adalah gambaran bahwa sampel yang berasal dari populasi berdistribusi normal dan hipotesis tandingan yaitu distribusi tak normal. Jika $\mathrm{H}_{0}$ diterima apabila nilai $p>0,05$, sedangkan jika $\mathrm{H}_{0}$ ditolak maka nilai $\mathrm{p}<0,05$ dan $\mathrm{H}_{\alpha}$ diterima.

b. Uji Homogenitas
Dengan menggunakan uji levene, data di uji apakah homogeny atau tidak dengan kriteria pengujian apabila nilai signifikansi (p) $>0,05$ menunjukan kelompok data berasal dari populasi yang memiliki varians yang sama (homogen). Namun apabila nilai signifikansi (p) $<0,05$ menunjukan tiap kelompok data berasal daridata populasi yang tidak yang sama (tidak homogen).

2. Uji Hipotesis

Uji data dilakukan dengan menggunakan SPSS. Dengan melalui beberapa tahap sebagai berikut: untuk mengetahui apakah metode ceramah dan metode eksperimen dapat meningkatkan hasil belajar siswa.

Selanjutnya untuk mengetahui metode eksperimen dapat meningkatkan keterampilan proses sains, digunakan uji $\mathrm{T}$ dengan tingkat signifikan 0,05 .

\section{HASIL DAN PEMBAHASAN}

Penelitian dilakukan pada tanggal 2 April17 April 2018 di SMA Negeri 1 Tondano, Minahasa. Subyek penelitian adalah 58 siswa kelas X MIPA yang dibagi secara acak menjadi 29 Kelas eksperimen dan 29 kelas kontrol.

1. Metode Kelas Eksperimen

\begin{tabular}{|l|l|l|l|l|}
\hline No & Kode & \multicolumn{2}{|l|}{ Pengetahuan } & KPS \\
\cline { 3 - 5 } & & $\begin{array}{l}\text { Pre-test } \\
(\%)\end{array}$ & $\begin{array}{l}\text { Post- } \\
\text { test } \\
(\%)\end{array}$ & $\begin{array}{l}\text { Post- } \\
\text { test }(\%)\end{array}$ \\
\hline 1 & $\mathrm{X}-1.1$ & 52 & 80 & 83 \\
\hline 2 & $\mathrm{X}-1.2$ & 46 & 74 & 75 \\
\hline 3 & $\mathrm{X}-1.3$ & 50 & 98 & 90 \\
\hline 4 & $\mathrm{X}-1.4$ & 71 & 93 & 85 \\
\hline 5 & $\mathrm{X}-1.5$ & 20 & 70 & 78 \\
\hline 6 & $\mathrm{X}-1.6$ & 38 & 67 & 79 \\
\hline 7 & $\mathrm{X}-1.7$ & 63 & 100 & 100 \\
\hline 8 & $\mathrm{X}-1.8$ & 37 & 73 & 89 \\
\hline 9 & $\mathrm{X}-1.9$ & 29 & 76 & 75 \\
\hline 10 & $\mathrm{X}-1.10$ & 45 & 80 & 90 \\
\hline 11 & $\mathrm{X}-1.11$ & 66 & 76 & 80 \\
\hline 12 & $\mathrm{X}-1.12$ & 46 & 75 & 78 \\
\hline 13 & $\mathrm{X}-1.13$ & 25 & 65 & 70 \\
\hline 14 & $\mathrm{X}-1.14$ & 44 & 85 & 89 \\
\hline 15 & $\mathrm{X}-1.15$ & 51 & 79 & 81 \\
\hline 16 & $\mathrm{X}-1.16$ & 39 & 69 & 74 \\
\hline 17 & $\mathrm{X}-1.17$ & 30 & 86 & 90 \\
\hline 18 & $\mathrm{X}-1.18$ & 53 & 76 & 89 \\
\hline 19 & $\mathrm{X}-1.19$ & 46 & 95 & 100 \\
\hline 20 & $\mathrm{X}-1.20$ & 66 & 75 & 71 \\
\hline 21 & $\mathrm{X}-1.21$ & 21 & 60 & 76 \\
\hline 22 & $\mathrm{X}-1.22$ & 54 & 80 & 85 \\
\hline 23 & $\mathrm{X}-1.23$ & 62 & 78 & 83 \\
\hline & & & & \\
\hline
\end{tabular}




\begin{tabular}{|l|l|l|l|l|}
\hline 24 & X-1.24 & 45 & 86 & 91 \\
\hline 25 & X-1.25 & 53 & 87 & 90 \\
\hline 26 & X-1.26 & 61 & 89 & 95 \\
\hline 27 & X-1.27 & 40 & 75 & 79 \\
\hline 28 & X-1.28 & 56 & 97 & 100 \\
\hline 29 & X-1.29 & 39 & 83 & 87 \\
\hline & $\begin{array}{l}\text { Rata- } \\
\text { rata }\end{array}$ & 46,46 & 80,24 & 84,55 \\
\hline
\end{tabular}

materi Usaha dan Energi, penghitungan uji $\mathrm{T}$ independent mengunakan software SPSS 22,0. Dan didapatilah hasil sebagai berikut pada tabel 1

2. Metode Kelas Kontrol

\begin{tabular}{|l|l|l|l|l|}
\hline No & Kode & \multicolumn{2}{|l|}{ Pengetahuan } & KTP \\
\cline { 3 - 5 } & $\begin{array}{l}\text { Pre- } \\
\text { test } \\
(\%)\end{array}$ & $\begin{array}{l}\text { Post- } \\
\text { test } \\
(\%)\end{array}$ & $\begin{array}{l}\text { Post- } \\
\text { test } \\
(\%)\end{array}$ \\
\hline 1 & X-2.1 & 50 & 75 & 80 \\
\hline 2 & X-2.2 & 50 & 74 & 73 \\
\hline 3 & X-2.3 & 50 & 85 & 85 \\
\hline 4 & X-2.4 & 59 & 64 & 80 \\
\hline 5 & X-2.5 & 23 & 70 & 75 \\
\hline 6 & X-2.6 & 38 & 67 & 70 \\
\hline 7 & X-2.7 & 45 & 64 & 56 \\
\hline 8 & X-2.8 & 37 & 70 & 60 \\
\hline 9 & X-2.9 & 29 & 65 & 72 \\
\hline 10 & X-2.10 & 45 & 80 & 78 \\
\hline 11 & X-2.11 & 65 & 76 & 65 \\
\hline 12 & X-2.12 & 42 & 75 & 70 \\
\hline 13 & X-2.13 & 30 & 68 & 71 \\
\hline 14 & X-2.14 & 45 & 80 & 79 \\
\hline 15 & X-2.15 & 65 & 79 & 78 \\
\hline 16 & X-2.16 & 36 & 69 & 71 \\
\hline 17 & X-2.17 & 45 & 83 & 80 \\
\hline 18 & X-2.18 & 53 & 76 & 70 \\
\hline 19 & X-2.19 & 46 & 78 & 65 \\
\hline 20 & X-2.20 & 66 & 75 & 71 \\
\hline 21 & X-2.21 & 21 & 60 & 76 \\
\hline 22 & X-2.22 & 29 & 62 & 85 \\
\hline 23 & X-2.23 & 48 & 78 & 83 \\
\hline 24 & X-2.24 & 45 & 75 & 76 \\
\hline 25 & X-2.25 & 53 & 85 & 87 \\
\hline 26 & X-2.26 & 61 & 76 & 67 \\
\hline 27 & X-2.27 & 40 & 75 & 78 \\
\hline 28 & X-2.28 & 56 & 79 & 62 \\
\hline 29 & X-2.29 & 60 & 82 & 80 \\
\hline & Rata-rata & 45,93 & 73,97 & 73,90 \\
\hline
\end{tabular}

Tabel 1

Perbandingan pretest \& post test hasil belajar kelas Eksperimen dan Kelas Kontrol Group Statistics

\begin{tabular}{|c|c|c|c|c|c|}
\hline & KELAS & $\mathrm{N}$ & Mean & Std. Deviation & $\begin{array}{l}\text { Std. Error } \\
\text { Mean }\end{array}$ \\
\hline PRET & EKSPERIMEN & 29 & 46,48 & 13,495 & 2,506 \\
\hline EST & KONTROL & 29 & 45,93 & 12,323 & 2,288 \\
\hline POST & EKSPERIMEN & 29 & 80,24 & 10,123 & 1,880 \\
\hline EST & KONTROL & 29 & 73,97 & 6,869 & 1,275 \\
\hline
\end{tabular}

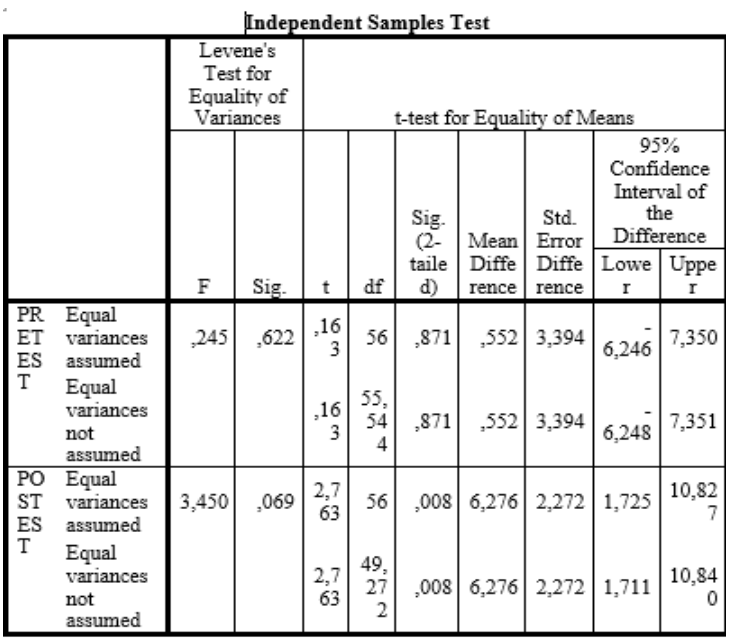

Berdasarkan hasil penghitungan dengan menggunakan software SPSS pada tabel 11, nilai mean pretest kelas control $=46,48$ dan nilai mean kelas eksperimen $=45,93$. karena nilai sig. $(2$-tailed $)=0,871>0,05$, maka tidak signifikan. Sedangkan pada posttes, nilai mean posttest kelas eksperimen $=80,24$ dan kelas kontrol $=73,97$. karena nilai sig. $(2$-tailed $)=$ $0,008<0,05$, maka signifikan. Kemudian membandingkan nilai $t$ hitung dengan $t$ tabel untuk sampel berjumlah 29. Dan untuk sampel berjumlah 29 dengan taraf signifikasi $\alpha=0,05$ memiliki t tabel : 1,669913. Dan untuk post test kelas eksperimen dan kelas control pada Independent Samples Test terdapat $\mathrm{t}$ hitung 2,763, dengan demikian t hitung 2,763>1,669 t tabel maka $\mathrm{H}_{0}$ ditolak. Dan $\mathrm{H} \alpha$ diterima sehingga dapat dikatakan ada perbedaan hasil post test antara kelas eksperimen dan kelas kontrol. Serta dapat disimpulkan bahwa hasil belajar pada kelas eksperimen yang menggunakan metode pembelajaran eksperimen lebih tinggi dari pada kelas control yang menggunakan metode ceramah aktif. 
a. Peningkatan hasil belajar

Dari hasil penelitian yang diperoleh selama penelitian terlihat bahwa kelas eksperimen dengan menggunakan metode pembelajaran Eksperimen dan kelas kontrol yang menggunakan metode cerama aktif, samasam terjadi peningkatan hasil pembelajaran. Sebuah pembuktian bahwa proses penerimaan pengetahui, bukan sesuatu yang langsung ditemukan namun merupakan hasil proses belajar.

Dan untuk materi Usaha dan Energi, metode eksperiman sangat efektif meningkatkan hasil belajar siswa. Terlihat dari hasil post test. anatara kelas eksperimen dan kelas kontrol, nilai mean masing-masing adalah 80,24 dan 73,90. Hasil belajar yang cukup meningkat bila di bandingkan dengan nilai pre test antara kelas eksperimen dan kelas kontrol, yaitu mean : 46,48 dan 45,93. Walaupun demikian terdapat signifikasi perbedaan mean antara hasil belajar dengan menggunakan metode pembelajaran eksperimen dan metode pembelajaran demonstrasi, selanjutnya hasilnya dianalisis menggunakan software SPSS 22,0 dengan menggunkan uji Independen sample t-test.

Berdasarkan uji Independen sample test, terlihat bahwa pada post test antara kelas eksperimen dan kelas kontrol memiliki t hitung 2,763>1,669 t tabel. Artinya terdapat perbedaan hasil belajar fisika antara siswa yang diajarkan dengan menggunakan metode pembelajaran Eksperimen dan siswa yang diajarkan dengan menggunakan metode demonstrasi.

Instrument pilihan ganda data hasil instrument tes dianalisis secara kuantitatif dan berdasarkan hasil analisis tes, diperoleh ratarata hasil belajar siswa kelas eksperimen 74,24 dan kelas control 69,28. Hal tersebut didasarkan hasil uji hipotesis dengan menggunakan uji t terhadap data posttes dengan $\mathrm{n}=25$ dan $\alpha=5 \%$. Hasil adalah nilai $\mathrm{t}$ hitung=2,80 sedangkan t table 2,20. Terlihat bahwa $t$ hitung> $t$ table, sehingga dapat disimpulkan bahwa terdapat penggaruh metode eksperimen terhadap hasil belajar siswa pada konsep usaha dan Energi.

b. Peningkatan keterampilan proses sains

Berdasarkan hasil posttest keterampilan proses sains kelas eksperimen dan kelas control pada Independent Samples Test terdapat $\mathrm{t}$ hitung 5,011, dengan demikian $t$ hitung 5,011>1,669 t tabel maka $\mathrm{H}_{0}$ ditolak. Dan $\mathrm{H} \alpha$ diterima sehingga dapat dikatakan ada perbedaan hasil post test antara kelas eksperimen dan kelas kontrol. Serta dapat disimpulkan bahwa keterampilan proses sains pada kelas eksperimen yang menggunakan metode pembelajaran eksperimen lebih tinggi dari pada kelas kontrol yang menggunakan metode pembelajaran demonstrasi.

Ditemukan nilai mean posttest pada kelas eksperimen $=76,35$ dan nilai mean pada kelas control 67,00. Sedangkan nilai $t=2,85$, $\mathrm{p}=0,007<\alpha=0,005$, yang menunjukan keterampilan sains dengan menggunkan metode eksperimen lebih meningkatkan keterampilan sains dibandingkan dengan metode eksperimen.

\section{KESIMPULAN}

a. Berdasarkan hasil uji SPSS terdapat nilai mean post test kelas Eksperimen $=80,24$ dan kelas kontrol=73,97, selanjutnya dengan menggunakan Independent Sample Test untuk membandingkan $t$ hitung dan $\mathrm{t}$ tabel. Dengan demikian $\mathrm{t}$ hitung 2,763>1669 t tabel maka $\mathrm{H}_{0}$ ditolak dan $\mathrm{H}_{\mathrm{a}}$ diterima sehingga dapat disimpulkan bahwa Penggunaan metode eksperimen dapat meningkatkan hasil belajar siswa kelas X MIPA SMA Negeri 11 Tondano pada materi Usaha dan Energi

b. Berdasarkan hasil post test keterampilan proses sains kelas eksperimen dan kelas control pada Independent Samples Test terdapat $\mathrm{t}$ hitung 5,011, dengan demikian $\mathrm{t}$ hitung 5,011>1,669 $\mathrm{t}$ tabel maka ${ }^{1} \mathrm{H}_{0}$ ditolak. Dan $\mathrm{H} \alpha$ diterima sehingga dapat dikatakan ada perbedaan hasil post test antara kelas eksperimen dan kelas kontrol. Sehingga dapat disimpulkan bahwa Penggunaan metode eksperimen dapat meningkatkan keterampilan proses sains siswa kelas X MIPA SMA Negeri 1 Tondano pada materi Usaha dan Energi.

\section{REFERENSI}

Astuti Rina, dkk, 2012. Pembelajaran ipa dengan pendekatan keterampilan proses sains menggunakan metode eksperimen bebas termodifikasi dan eksperimen terbimbing ditinjau dari sikap ilmiah dan motivasi belajar siswa. Jurnal Inquiri. ISSN : 2252-7893, Vol 1. No 1 2012. $\quad$ http://jurnal.pasca.uns.ac.id (diakses 22 juni 2018) 
Amalik, Oemar. 2006. Proses Belajar Mengajar. Jakarta: PT. Bumi Aksara

Bernadetta Savitri Sutasoma.2016. Pengaruh metode eksperimen terhadap peningkatan hasil belajar dan keterampilan proses sains pada pokok bahasan perubahan wujud zat untuk kelas X SMA Negeri 1 Kaihan Bantul. Skripsi jurusan pendidikan fisika, Universitas Sanata Darma Yogyakarta.

http://repository.usd.ac,id/6515/2/121424 O25_full.pdf (diakses 19 Februari 2019)

Bustami, dkk. 2014. Statistika Terapannya di Informatika, Yogyakarta: Graha ilmu.

Choirul Mahfud (2013). Perndidikan Multikultural. Yokyakarta : Pustaka Pelajar

Djamarah, B Syaiful dan Zain, Aswan. 2006. Strategi Belajar Mengajar. Jakarta: PT.Rineka Cipta

Firman Mauluddin Nurhidayat ${ }^{1}$, Rina Riani², Anugrah Rahmadhan Firdaus 3 "Aplication of experimental methods to improve learning outcomes class $V$ students on science learning abaut light properties" journal of elementary education Vol. 01 number 2 march 2018. E-ISSP 2614-4093.

Hamadani, 2011. Strategi Belajar Mengajar, Bandung : CV Pustaka Setia

Insana Damopoli, 2018. "Meningkatkan Keterampilan Proses Sains dan Hasil Belajar Siswa Melalui pembelajaran Berbasis Inquari" jurnal Bioedukatika. Vol. 6. No. 1 Tahun 2018. Universitas Ahmad Dahlan. http://www.researchagate.net/signup.html (diakses 3 desember 2018)

M Ardi Setyanto. (2014). Panduan Sukses Komunikasi Belajar-Mengajar. Yokyakarta : Diva Press

S.Wahyuni ${ }^{1 *}$, Indrawati ${ }^{1}$, Sudarti ${ }^{1}$, W.Suana ${ }^{1}$ "Developing science process skills and problem-solving abilities based on outdoor learning in junior high school"JPII 6(1)(2017)165-169. http://journal.unnes.ac.id/index.php/jpii (diakses 3 desember 2018)

Slameto. 2010. Belajar dan faktor-faktor yang mempengaruhi Cet V. Jakarta : Rineke cipta

Soetjipto, Raflis Kosasi. (2004). Profesi Keguruan. Jakarta : PT. Asdi Mahasatya.

Sulastiani, dkk. 2012. "Analisis keterampilan proses melalui metode eksperimen dalam pembelajaran fisika pada siswa kelas VIII SMP Negeri 1 Makasar" jurnal sains dan pendidikan fisika. Jilid 8. No. 3, Desember 2012, hal 257-261. Universitas Negeri Makasar.

http://ojs.unm.ac.id/JSdPF/article/downlo ad/920/211 (diakses 23 November 2018)

Trianto. 2012. Metode Pembelajaran terpadu : konsep, strategi dan implementasi dalam kurikulum Tingkat Satuan Terpadu (KTSP). Jakarta : Bumi Aksara 